toxic, surface-active cations, and suggested that the basis for the antibacterial action of such cations could be satisfactorily described in terms of cationic exchange.

Bliss, Chandler and Schoenbach ${ }^{5}$ found that polymyxin was inactivated by soap, lipositol and other substances known to antagonize cationic detergents. The results reported above, togethor with those of Newton ${ }^{2,3}$ and Few and Schulman ${ }^{6}$, further support the resemblance between cationic detergents and polymyxin, although cationic detergents are generally far more effective against Gram-positive than Gramnegative organisms, whereas polymyxin is more active against the latter.

Medical Research Council Unit

B. A. NEwToN

for Chemical Microbiology,

Biochemical Laboratory,

University of Cambridge. April 29.

${ }^{1}$ Jackson, D. M., Lowbury, E. J. I., and Topley, E., Lancet, ii, 137 (195I).

"Newton, B. A., J. Gen. Microbiol., 8, vi (1953).

${ }^{3}$ Newton, B. A., J. Gen. Microbiol. (in the press)

- Valko, E. I., and DuBois, A. S., J. Bact., 47, 15 (1914).

${ }^{5}$ Bliss, E. A., Chandler, C. A., and Schoenbach, E. B., Ann. N.Y.

- Few, A. V., and Schulman, J. H., Nature, 171, 644 (1953).

\section{A Colorimetric Estimation of Sugars using Benzidine}

A solution of benzidine in acetic acid has been used by Horrocks and Manning ${ }^{1}$ as a chromatographic spray reagent for the detection of sugars. A quantitative technique, using this reagent, has been perfected and found to be satisfactory for the majority of common sugars (cf. McCance ${ }^{2}$ ) and their methylated derivatives with the exception of ketoses. Concentrations as low as $0.1 \mathrm{mgm} . / \mathrm{ml}$. were estimated, with errors of less than 3 per cent.

The procedure for estimation was as follows. $1 \mathrm{ml}$. of sugar solution and $5 \mathrm{ml}$. of 0.2 per cent $(\mathrm{w} / \mathrm{v})$ benzidine in glacial acetic acid were placed in a boiling-tube and heated in a vigorously boiling water-bath. The heating time necessary for maximum colour production varied with the nature of sugar being estimated (see table). After cooling to room temperature in running water, the orange-yellow coloration was measured with a Hilger Spekker (Ilford No. 601 filter). The relationship between concentration and absorption was linear for the following sugars :

\begin{tabular}{|c|c|}
\hline Sugar & $\begin{array}{l}\text { Heating time } \\
\text { (min.) }\end{array}$ \\
\hline Glucose & 30 \\
\hline Mannose &, \\
\hline Galactose & $"$ \\
\hline Glucuronic acid & , \\
\hline Galacturonic acid & ," \\
\hline Rhamnose & \\
\hline Arabinose & 15 \\
\hline Ribose & ", \\
\hline $\begin{array}{l}\text { Xylose } \\
2: 3: 4 \text {-Trimethyl xylose }\end{array}$ & 60 \\
\hline $2: 3: 6$-Trimethyl glucose & $"$ \\
\hline 2:4:6-Trimethyl glucose & ," \\
\hline $2: 3: 4: 6$-Tetramethyl glucose & $"$ \\
\hline $\begin{array}{l}\text { Sucrose } \\
\text { Maltose }\end{array}$ & $\ddot{\prime}$ \\
\hline Maltose & ". \\
\hline
\end{tabular}

Polysaccharides have been analysed by the now method, quantitative separation of the monosaccharide components being effected by paper partition chromatography. Sugars were extracted from the papsr with hot 90 per cent methyl alcohol, and the methanolic sugar solution evaporated down to a syrup in vacuo. The required volume of distilled water was then added, and a 1-ml. aliquot of the solution taken for analysis. Standard sugar mixtures separated by the above procedure were estimated with errors of 3-5 per cent.

The mechanism of the reaction has been examined and it appears that molecular equivalents of benzidine and sugar (having a free or easily accessible aldehyde group) combine to give a coloured compound.

The mild nature of the reagents used, and the wide range of sugars which can be estimated, are the two main advantages of the new method.

A detailed report of experimental method, results, and applications will be published elsewhere.

J. K. N. Jones

J. B. PridhaM

Department of Biological Chemistry, University, Bristol 8.

${ }^{1}$ Horrocks, R. H., and Manning, G. B., Lancet, 258, 1042 (1949).

${ }^{2}$ MeCance, R. A., Biochem. J., 20, 1111 (1926).

\section{Isolation and Biochemical Function of the Golgi Substance}

RECENT studies have demonstrated the positive image of the Golgi substance in epithelial cells of the mouse opididymis with the phase-contrast microscope ${ }^{1}$. In situ, the Golgi substance was found to possess characteristic optical properties with phasecontrast and dark-field illumination, and to be completely refractory to staining with methylene blue and neutral red. Examination of cells of the head of the epididymis of the rat and the mouse immediately after or during crushing clearly indicated that the Golgi substance retained its general form and its specific optical properties upon release from its intracellular environment. Experiments to determine the most suitable medium for the maintenance of the Golgi substance extracellularly indicated that the presence of $0.34 M$ sodium chloride was essential and that the addition of sucrose in concentrations ranging from 0.25 to $1.25 M$ to the saline medium had no appreciable effect on the morphology, optical properties or stability of the Golgi substance.

The isolation of the Golgi substance was accomplished by a modification of the method of Brakke ${ }^{2}$, which we have used with some success in the fractionation of isolated liver mitochondria ${ }^{3}$. A 20 per cent homogenate of rat epididymis in $0.25 M$ sucrose was prepared $^{4}$, layered over a sucrose density-gradient consisting of $1.0-\mathrm{ml}$. layers of $0.335,0.636,0.957$ and 1.11 $M$ sucrose, each containing $0.34 M$ sodium chloride, and centrifuged for $60 \mathrm{~min}$. at 35,600 r.p.m. (108,000 $g$ average) in the $S W 39$ horizontal rotor of a Spinco Model $E$ ultracentrifuge. The Golgi substance was found to sediment in a sharp yellowish band $2-3 \mathrm{~mm}$. wide at the bottom of the $0.636 \mathrm{M}$ sucrose layer (Fig. 1) ; and since clear layers at least $5 \mathrm{~mm}$. wide were present on either side of the Golgi band, it was found possible to separate this band by cutting the centrifuge tube at appropriate points. Microscopic examination of the separated Golgi layer showed that it contained large clumps of bodies with the optical properties under phase- and dark-ground illumination (Fig. 2) characteristic of the Golgi substance as it is seen in the intact cell and extracellularly 